\author{
AMERICAN JOURNAL OF FOOD AND NUTRITION \\ Print: ISSN 2157-0167, Online: ISSN 2157-1317, doi:10.5251/ajfn.2011.1.2.61.66 \\ (C) 2011, ScienceHuß, http://www.scihub.org/AJFN
}

\title{
Origin and propagation of Chromolaena odorata (L.) king and robinson (Asteraceae) between Mabele and Meiganga in the North of Cameroon
}

\author{
Dibong Siegfried Didier ${ }^{{ }^{*}}$, Ndiang Zenabou ${ }^{1}$, Ondoua Joseph Marie ${ }^{1}$, Bilong Paul ${ }^{2}$ \\ ${ }^{1}$ Department of Botany, Faculty of Science, The University of Douala, P.O. Box 24157 \\ Douala, Cameroon. \\ ${ }^{2}$ Department of Earth Science, Faculty of Science, University of Douala, P.O. Box 24157 \\ Douala, Cameroon. \\ * Corresponding author: didierdibong@yahoo.fr
}

\begin{abstract}
Chromolaena odorata is an Asteraceae with ill-fated consequences in some regions of Cameroon because of its high capacity of spreading and invasion.A study realized between Mabele and Meiganga, in the forest-savanna transition zones located on the right bank of the river Lom, concerns the spreading and the regeneration of $C$. odorata. The worry aroused after the laying of the pipeline is that the building works should have favoured the spreading of this Asteraceae which highly reduces pasture zones knowing that it is a breeding zone par excellence. The aim of this study was to demonstrate that this species was existing in this huge region which goes from the Central Africa Republic to Nigeria, quite before the beginning of the Chad-Cameroon pipeline building works in 2002. The inversion of soils' polarity would have probably brought about the burying of some $C$. odorata's spores. The study of the transect realized in the Mabele-Meiganga area indicates that two generation types of $C$. odorata coexist on the area: on areas that are not disrupted by the building construction work, are located very robust old stumps of $C$. odorata which easily reach two meters height; and on the ROW (Road Of Way), are located young stumps of this species with very fragile and willowy stems. Knowing also that $C$. odorata is pioneer species; its presence here seemed natural because it has been later replaced by typical forest or savanna's species. This study shows that $C$. odorata's density decreases as one goes along from the forest to the shrubby or grassy savanna. Although the pipeline building works should have favoured the burying of this Asteraceae's spores, its presence should be linked to a climate zonation promoted by the $C$. odorata's fact is also a pioneer species. This study shows that the impact of the Chad-Cameroon pipeline building works would probably be negligible.
\end{abstract}

Keywords: Chromolaena odorata, forest-savanna contact, spreading, Mabele, Meiganga.

\section{INTRODUCTION}

Problems caused by Chromolaena odorata all over the World and specifically in Cameroon do not spare the East and the Adamaoua regions. Then, it is deservedly that many authors consider $C$. odorata as a "vegetable plague" which should be eradicated (Hubert de Foresta and Schwartz, 1991).

A study worked out on $C$. odorata species on the left bank of the river Lom, especially in the Kendara savanna in the East region of Cameroon by Achoundong (1988) was shown that this Asteraceae appeared in the region probably under the cover of the Dimako-Batouri trail creation in the 1960's and was begun to be encroaching from the 1970's, period during which it had settled down in the fields established in the forest or the savanna zone.
Another study carried in Central Africa by Boutrais (1988) was shown that C. odorata's baneful incidence on pastoral locals had begun to bring home in the 1980's to Baboua, a central african locality situated at some kilometers from Garoua-Boulai, a Cameroon frontier town. The nearness of the two regions and their height situation $(930 \mathrm{~m})$ also was suggested the presence of this Asterceae on both side of the border at the same period.

Kandara and Garoua-Boulai regions were then considered as principal focal points of Chromolaena odorata's spreading towards Cameroon's Northern provinces. Garoua-Boulai, which was belonging to the study zone, had facilitated the following of $C$. odorata's spreading towards the North. C. odorata could also derive from the forest zone located in the South of Meiganga. 
In fact, in the both cases, the seeds of $C$. odorata could remain buried in the soil during five years (Vanderwoude et al., 2005), it was expected from C. odorata to have a high reappearance in places that had undergone a turning up of soil by heavy engines.

The East and the Adamaoua provinces was constituted vast pasture zone which were completely reduced by Chromolaena odorata's spreading. There were existed three types of $C$. odorata spore spreading: by the wind, the livestock and the anthropic action through building works or main roads maintenance. At the time of the Chad-Cameroon pipeline building, engines had crossed vast zones. The variability of seasons and the presence of $C$. odorata in the South forest zone had arose the thought that the pipeline's building should have entailed the spreading of $C$. odorata from the South to the North with the reduction of pasture zones as a consequence. The aim of the present work was to show through transects, the incidence of the pipeline building works on the spreading of $C$. odorata in these zones.

\section{MATERIAL AND METHODS}

Methods: These stages had been realized on the ground for this work:

- The general prospecting of the study zone;

- The making of study itinerary;

- The determination of Chromolaena odorata's medium recovering per list of the chosen site.

The prospecting of the study zone

The prospectings had been done by train on the track from Yaounde to Ngaoundal, then by overland from Ngaoundal to Ngaoundere via Garoua-Boulai, Meiganga and Ngaoui by using a 4WD vehicle. The surface covered was about $16.538 \mathrm{~km}^{2}$ (Figure 1)

Making of itineraries: The making of itineraries had been done after the prospecting of the study zone and by learning on Cameroon's phytogeographic maps (Letouzey, 1968, 1985).

The study zone was the one of the shrubby savanna demarcated in the South of Meiganga by the forestsavanna contact at Pangar; its medium height was $776 \mathrm{~m}$. In the North, this zone was in touch with the grassy savanna's domains from Ngaoundere (medium altitude 1085m). Four itineraries (Figure 2) had been made from the approximate lay-out of the Chad-Cameroon's pipeline, orientated SouthWest/North-East from Mabele to Mbaiboum.

Two itineraries NW-SE which had cut perpendicularly the pipeline Chad-Cameroon whose first one was in the South (road NW-SE, H1) and the second one in the North (road NW-SE, H2). The road NW-SE 1H1 had crossed successively the following localities: Garoua-Boulai, Beka, Lokoti, Meidougou, Badjei and Ngaoundal of $300 \mathrm{~km}$. The itinerary NW-SE, $1 \mathrm{H} 2$ went from Ngoui to Dibi via Djokong, Meiganga, Babongo, Nyambaka, Bandal; the distance covered was $245 \mathrm{~km}$.

Two itineraries SW-NE was orientated in the direction of Chad-Cameroon pipeline's lay-out. The first itinerary (SW-NE, V1) was put back from the ChadCameroon pipeline of $50 \mathrm{~km}$ and was parallel to the pipeline. It went from Pangar (in the South) to Dibi (in the North) via Ngaoundal and was measured 143km. The second itinerary (SW-NE, V2) had crossed the localities situated along the Chad-Cameroon pipeline's circuit and was measured about $93 \mathrm{~km}$ by road. The concerned were Mabele, Meidougou and Meiganga.

Determination of the medium recovering: For every realized itinerary, and in each locality reserved as a study site, one list has been carried out on a surface of $100 \mathrm{~m}^{2}(20 \times 5 \mathrm{~m})$ each by using the signs amongst those defined by Braun Blanquet (1932) to characterize the spreading of $C$. odorata; these signs are: the presence and the abundance dominance.

The presence As it name points out, this sign is used to show the presence of a species on a list. The following signs are allot to each species:

$+:$ to indicate that the species is present in the milieu;

-: to indicate the absence of the species.

The abundance dominance

The abundance is the number of individuals per unit of surface or volume and the dominance corresponds to the surface covered by one species.

Braun Blanquet (1932) for useful reasons has introduced a mixed coefficient of abundancedominance to show the recovering's degree of a species with a scale from 1 to 5 :

+ : sparse individuals covering up less than $1 / 2$ of the surface;

1: less numerous individuals covering up $1 / 20$ of the surface;

2: abundant individuals covering up from $1 / 20$ to $1 / 4$ of the surface;

3 : individuals covering up from $1 / 4$ to $1 / 2$ of the surface; 4: individuals covering up from $1 / 2$ to $3 / 4$ of the surface; 5: individuals covering up more than $3 / 4$ of the surface. These signs are afterwards turned into medium recovering:

+ : individuals taking up $0.5 \%$ of the list surface;

1: individuals taking up $3 \%$ of the list surface;

2: individuals taking up $15 \%$ of the list surface;

3: individuals taking up $37.5 \%$ of the list surface;

4: individuals taking up $62.5 \%$ of the list surface;

5: individuals taking up $87.5 \%$ of the list surface.. 


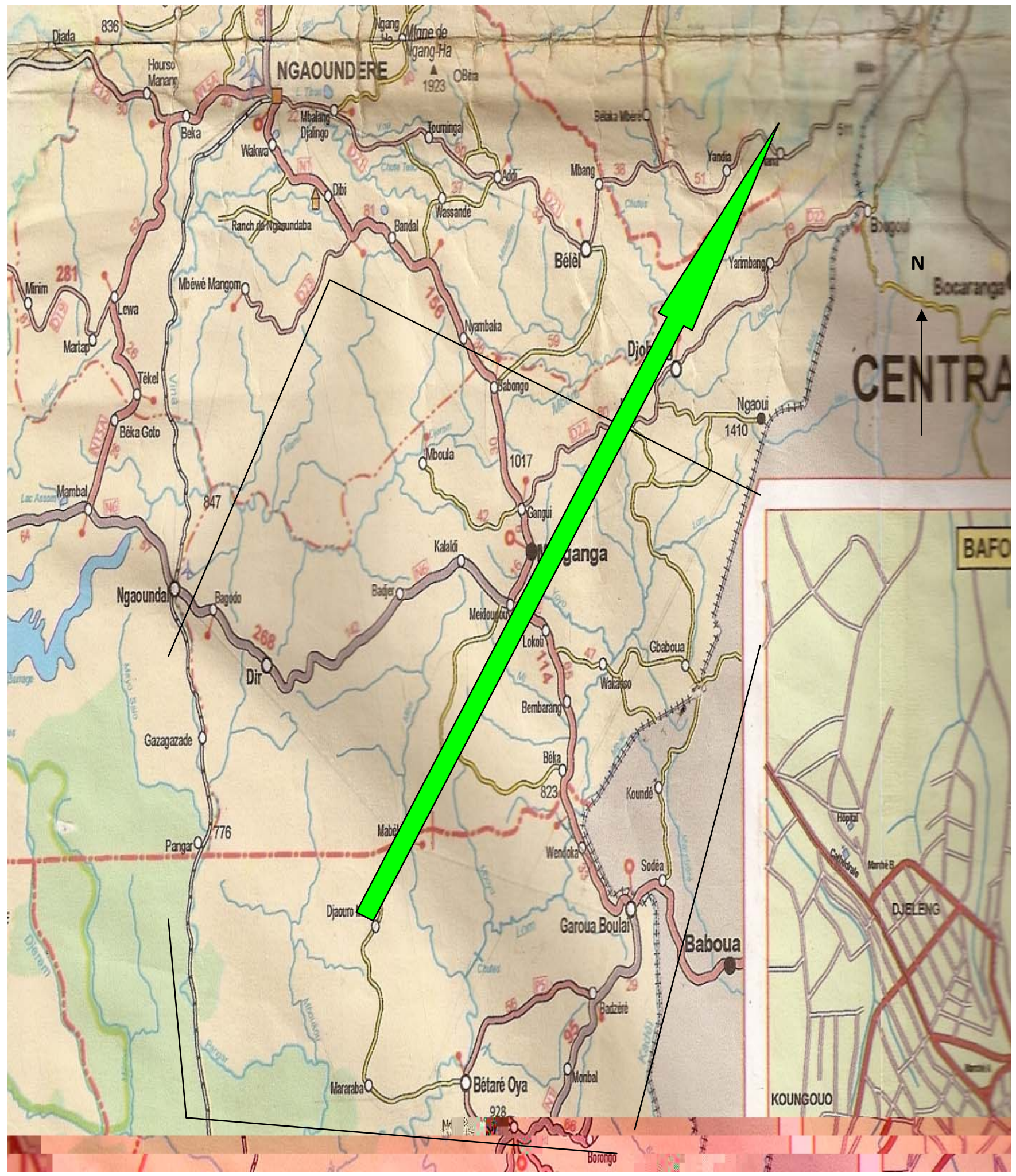

Fig 1 : Region of Adamaoua (Study region) extraited of the road map of Cameroon (1/1500 000). 
Am. J. Food. Nutr, 2011, 1(2): 61-66

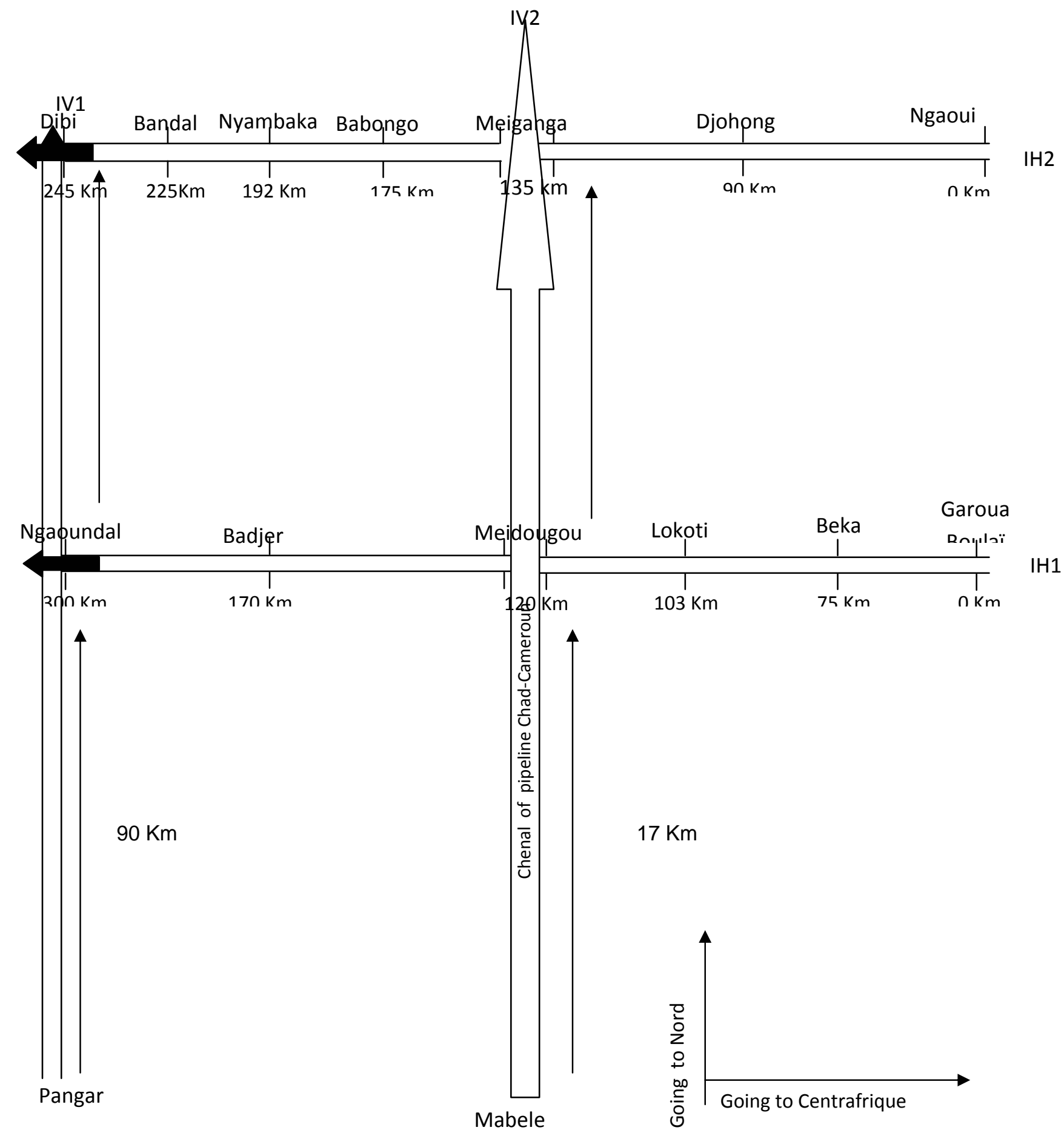

Fig 2 : Made itineraries.

Legend: IH1: Itinerary NW-SE ${ }^{\circ} 1$; IV1: Itinerary SW-NE $n^{\circ} 1$

\section{RESULTS}

Description of NW-SE and SW-NE itineraries and surveys done
NW-SE, H 1 itinerary

The NW-SE, H 1 itinerary was 300m long and was going from Ngaoundal to Garoua-Boulai (Table I). 
The ROW (Road of Way) was divided it in two unequal parts:

- The first part was located in the Cameroon inland goes from Ngaoundal to Meidougou, about $180 \mathrm{~km}$ from the rail station of Ngaoundal;

- The second part wasgoing from Meidougou on the way to Garoua-Boulai towards central Africa and was $120 \mathrm{~km}$ long.

Six stations had been chosen for the making of transcripts. In each station, a transcript of $100 \mathrm{~m}^{2}$ surface had been made up. On this transcript, two clues of Braun Blanquet (1932) vegetation characterization are used: presence and abundancedominance. These numerical facts had enabled to obtain the medium recovering of $C$. odorata along the NW-SE, H 1 itinerary (Table I).

Going from the ROW, the spreading of $C$. odorata was done from Central Africa towards the country inland. In fact, the medium recovering had moved from $62.5 \%$ at Meudougou to $3 \%$ towards Ngaoundal. However, this recovering had increased between Meidougou and Garoua-Boulai and had moved from $3 \%$ to $87.5 \%$.

The NW-SE, $\mathrm{H} 1$ itinerary had shown that $C$. odorata's medium recovering was stepped up gradually from Cameroon interior (Ngaoundal) towards Central African Republic (Garoua-Boulai). In these conditions, $C$. odorata central african's origin was certified.

Table I

NW-SE, H 2 itinerary

The road NW-SE, $\mathrm{H} 2$ was separated at $30 \mathrm{~km}$ from the road NW-SE, H 2 in the North. Altitudes had varied between 1013 and 1200m (Table II).

The distance covered by this route was $245 \mathrm{~km}$ from Dibi (100km from Meiganga) to Ngaoui $(145 \mathrm{~km}$ from Meiganga). Ngaoui was located in the North of Garoua-Boulai (almost at the same altitude) and was a Central Africa Republic border locality.

The spreading done done from Central Africa towards Cameroon's interior and was more decided at the ROW level, because $C$. odorata's medium recovering had decreased gradually between Garoua-Boulai and Ngaoundal. The central african origin of $C$. odorata in its stations was then more certified (Table II).

Table II

SW-NE, V 1 itinerary
The SW-NE, V 1 itinerary was going from Pangar downstream to Dibi (towards Ngaoundere) upstream. It was situated out of the ROW and was $143 \mathrm{~km}$ long; altitudes had varied between $776 \mathrm{~m}$ and $1200 \mathrm{~m}$.

The spreading was done from Pangar to Dibi in keeping with the altitude and the vegetation (Table III).

Table III

\section{SW-NE, $V 2$}

The SW-NE, V 2 itinerary was followed the pipeline Chad-Cameroon's lay-out and was crossed the Mabele, Meiganga localities from the South through the North $93 \mathrm{~km}$ in total. Altitudes had varied from $980 \mathrm{~m}$ at Mabele and $1013 \mathrm{~m}$ at Meiganga.

The C.odorata's medium recovering was high and almost constant in these localities (Table IV).

Table IV

\section{DISCUSSION}

Chromolaena odorata was pointed out at Baboua, then at Garoua-Boulai in 1985 by Boutrais (1985). The study of $C$. odorata's populating densities through the recovering signs had shown that $C$. odorata was more abundant through the border localities of the Central Africa Republic: GarouaBoulai and Ngaoui. Afterwards, this abundance had decreased evenly towards the country interior until Ngaoundal proving the central africa origin of $C$. odorata. The confirmation was given by the $C$. odorata's medium recovering histogram along the NW-SE, H2 where the Asteraceae had decreased evenly from Ngaoui (towards Central Africa Republic) until Dibi inwards the country with however an accentuated regeneration due to the pipeline building works.

Two biotic factors of scattering were likely to have induced the spreading of $C$. odorata in Cameroon from Baboua (Central African locality situated at the border with Cameroon in Garoua-Boulai) about 1980 (Boutrais, 1988); it was a question of wind and oxen herds' shiftings.

Observations done on SW-NE itineraries also had shown a C. odorata's starting-point from South Cameroon. The spreading of Chromolaena odorata was influenced by abiotic factors which were the winds and the rivers (hydric rate), the vegetation and the altitude.

The scattering of Chromolaena odorata had seemed to be first of all the consequence of the wind. After Vanderwoude et al. (2005), practical tests were proved that seeds were scarcely scattered at more 
than $80 \mathrm{~m}$ from the main plant. Considering GarouaBoulai as the starting point of $C$. odorata's scattering, where it was settled down since, the wind could not be taken as the scattering agent of its presence in Meidougou (120km of Garoua-Boulai) towards the West. In fact, the biological cycle if $C$. odorata from the germination to the dispersal of seeds was continued for a year (Vanderwoude et al., 2005). For a near to near scattering which was $80 \mathrm{~m} /$ year, a diaspore going from Garoua-Boulai to reach Meidougou would need about 150 years. The wind impact on $C$. odorata's scattering was secondary.

Although C. odorata's seed was not palatable for birds' consumption, it was possible that they were getting across the seeds of this Asteraceae in their searching for other seeds or preys (Vanderwoude et al., 2005).

The oxen herds that were shipped to Yaounde by train axis like: Garoua-Boulai-Meidougou-Ngaoundal; Ngaoui-Meiganga-Meidougou-Ngaoundal were $C$. odorata's scattering potential vectors which had stick to their coat or their hooves. The $C$. odorata had fur lined further to the regeneration could then cover about a several hundred hectares in some years (Huguenin and Bedje-Bedogo, 1992b).

Some ecological factors were influenced the spreading of Chromolaena odorata especially the vegetation and the altitude.

The decrease of Chromolaena odorata's spreading along the vertical SW-NE, V 2 itinerary had shown that the vegetation influences this process. Indeed at pangar which was located in the forest-savanna contact zone, C. odorata had occupied the forest fringes where, due to its fats growth, was progressing fastly than the Gramineae it had deprives of light (Achoundong, 1988). Ngaoundal was a shrubby savanna zone at Albizzia sp.,Terminalia glaucescens, Harungana madagascariensis, Entada africana often linked to C. odorata. When at Dibi, the savanna was grassy with Imperata cylindrica and with Sacciolepsis sp.which had mortgaged the presence of $C$. odorata.

\section{CONCLUSION}

The study sets about between Mabele and Meiganga was intended to disclose the source of this plant and the pipeline Chad-Cameroon's impact on the scattering of this Asteraceae.

All the results obtained had shown that $C$. odorata was already present on the study zone in the 1980's far before the pipeline Chad-Cameroon building; some authors had pointed it out in Baboua. $C$. odorata had then a central african origin. The main spreading agents were the wind and the oxen herds. The Chad-Cameroon pipeline channel was not at the source of $C$. odorata's presence on the study region; nevertheless, it was facilitating the regeneration of this Asteraceae.

The dating of $C$. odorata in the different study environments through radioactive methods against this Asteraceae will more concur to a good control of this encroaching plant.

\section{ACKNOWLEDGMENTS}

We deeply thank Cameroon Oil Transport Corporation for their financial support.

\section{REFERENCES}

Achoundong, G. (1988). Dynamique des contacts forêtssavanes. Zone de Ngoro-Nguila et Mbitom. Rapport de la prospection botanique. MESIRES-Herbier National, Yaoundé.

Boutrais, J. (1988). Des Peuls en savanes humides. Développement pastoral dans l'Ouest Centrafricain. Paris. ORSTROM. Collection Etudes et Thèses, 283 p.

Braun-Blanquet, J. (1932). Plant sociology. The study of plant communities. Mc Graw-Hill, New-York. 405 p.

Hubert de Foresta, Schwartz, G. (1991). Chromolaena odorata and disturbance of natural succession after shifting culturation: An example from Mayombe, Congo, Central Africa. In: Muniappan R and Ferran P (Eds) Ecology and Management of Chromolaena odorata. BIOTROP Spec. Publ. 44: 23-41.

Huguenin, J., Beldje-Bedogo (1992). Travaux de recherche appliquée pour la protection des savanes pastorales en RCA contre Chromolaena odorata. In annales de la 7ème conférence de l'AIEMVT à Yamoussoukro, Côte d'Ivoire, 14-19 septembre 1992. Maisons-Alfort, CIRAD-EMVT, 9 p.

Letouzey, R. (1968). Etude phytogeographique du Cameroun, Paul Le chevalier, Paris. 508p. + cartes et ill.

Letouzey, R. (1985). Carte phytogéographique du Cameroun au 1: $500000 n^{\circ}$ 4. IRA-ICIV., Université de Toulouse, $240 \mathrm{p}$.

Vanderwoude et al. (2005). Plan for National Delimiting Survey For Siam Weed. Natural Resources and Mines Land Protection Service. Queensland Government. 